\title{
Türkiye'de Yeşil Ekonomi Açısından Yenilenebilir Bir Enerji Kaynağı: Rüzgar Enerjisi
}

\author{
Ahmet ÖZEN* \\ Mahmut Ünsal ŞAŞMAZ** \\ *Dokuz Eylül Üniversitesi İïF Maliye Bölümü, İzmir \\ **Uşak Üniversitesi İ̈BF Maliye Bölümü, Uşak
}

\author{
Ercan BAHTIYAR**
}

Özet

Günümüz toplumlarının gereksinimlerini, gelecek nesilleri olumsuz etkileyebilecek sonuçlar doğurmadan, karşılamayı hedeflemeleri sürdürülebilir kalkınma şeklinde nitelendirilmektedir. Bu tür kalkınma yeşil ekonomi şeklinde bir ekonomik modeli ifade etmekte olup, bu tür ekonomi politikası dünya genelindeki ülkelerin ortak hedefi haline gelmiştir. Bu amaçla birçok ülke enerji üretimini fosil yakıt yerine, yenilenebilir enerji kaynaklarının kullanılması suretiyle gerçekleştirmeyi politika olarak belirlemiştir. Yenilenebilir enerji kaynakları; rüzgar, güneş ışı̆̆ı, hidrogüç ve jeotermal olmakla birlikte, içlerinde önem sırasına göre ise rüzgar başta gelmektedir. Nitekim çalışma kapsamında yeşil ekonomi açısından önemli bir faktör olan rüzgar enerjisi kavramı üzerinde durulmuş ve bu bağlamda Türkiye'de rüzgar enerjisinin mevcut durumu incelenmiştir. Netice itibariyle Türkiye'de rüzgar enerjisine yönelik gelecek hedeflerine ulaşma konusunda nelerin yapıldı ğı ve nelerin yapılabileceği genel çerçevede ele alınmıştır.

Anahtar Kelimeler: Sürdürülebilir Kalkınma, Yenilenebilir Enerji, Rüzgar Enerjisi

\section{A Renewable Energy Source in Terms of Green Economy in Turkey: Wind Energy}

\begin{abstract}
Sustainable development is defined as aiming to satisfy the needs of the present societies without leading consequences which maybe affect the future generations negatively. This kind of development implies an economic model in the form of green economy and this kind of economic policy has become a common goal of all the countries in the world. For this purpose many countries decided to fulfill energy production by using renewable energy sources instead of fossil fuel. Renewable energy sources are wind, sunlight, hydropower and geothermal and wind is in the lead in order of priorities. Thus we focused on the wind energy concept which is an important factor in the context of the study and in this regard we examined the current situation of wind energy in Turkey. Consequently we evaluate what we have done and what we can do to reach the future goals for wind energy in Turkey.
\end{abstract}

Key Words: Sustainable Development, Renewable Energy, Wind Energy

\section{Giriș}

Sürdürülebilir kalkınma ve yeșil ekonomi günümüz iktisadi terminolojisinde hakim olmaya başlamış önemli kavramlardır. İnsanların temiz bir çevreye sahip olmalarının sağlanması prensibi ve iktisadi üretimin gelişimi ikilemini kırmak amacıyla oluşturulmuş bu tür kavramlar, dünyanın bize miras kalmadığını, aksine bizim gelecek nesillere taşımamız gereken bir emanet olduğunu vurgulamaktadır. Bu doğrultuda pek çok ülke tarafindan Kyoto Protokolü ve Montreal Protokolü gibi bir dizi uluslararası anlaşma da imzalanmış bulunmaktadır. Bu tür anlaşmalarla pek çok ülke enerji kaynağı olarak fosil yakıtlardan uzaklaşmayı ve yerine yenilenebilir enerji kaynaklarının tesisini sağlamayı hedeflemektedir.

Yenilenebilir enerji kaynağı kavramı üzerinde odaklanıldığı zaman başta güneş enerjisi ve rüzgar enerjisi akla gelmektedir. Elbette bunlar dişında da jeotermal, hidrolik, dalga ve hidrojen gibi çeşitli enerji kaynakları da bulunmaktadır. Ancak önem sırasına göre güneş enerjisi ve rüzgar enerjisi diğerlerine nazaran başat olma özelliği taşımaktadır. Nitekim bu çalışmada rüzgar enerjisi inceleme konusu yapılarak, yeşil ekonomiye yönelen çeşitli ülkelerdeki kullanım düzeyleri üzerinde durulacaktır. Ayrıca 2023 hedefine yönelen Türkiye'nin mevcut rüzgar enerjisi kapasitesi de ortaya konularak, bu enerji türüne yönelik bir dizi teşvikler hakkında açıklamalara yer verilecektir.

\section{Türkiye'de Yeşil Ekonomiye Geçiş Süreci}

Dünyada gittikçe daha fazla kullanım alanı bulan ve bu amaçla özellikle gelişmiş ülkelerin toplam enerji ihtiyaçlarının azımsanmayacak kadar önemli bir kısmını karşıladıkları yenilenebilir enerji kaynakları, iktisadi hayatta yeşil ekonomi kavramının gelişimini destekleyici unsurlar 
olarak karşımıza çıkmaktadır. Yeşil ekonomi kavramı ise doğayla uyumlu, çevreye negatif dişsallık oluşturmayan ve sürdürülebilir bir sosyo-ekonomik hayat tarzını ifade etmektedir. Bu kısımda yeşil ekonomi kavramsal bir bakış açısıyla ele alınacak ve Türkiye'de bu doğrultuda atılan adımlar kronolojik bir perspektifle inceleme konusu yapilacaktır.

\subsection{Yeşil Ekonomi Kavramı}

Günümüz dünyasında tasarruf ve üretimin aynı anda gerçekleştirildiği ve bu noktada doğal çevrenin gördüğü zararın minimalize edildiği bir ekonomik modele geçilmesi temel hedef olarak ön plana çıkmaktadır. $\mathrm{Bu}$ yönde benimsenmiş olan yeni ekonomi kavramı "yeşil ekonomi" şeklinde nitelendirilmektedir. Birleșmiş Milletler Çevre Programı (UNEP) tarafindan yapılan tanıma göre yeşil ekonomi; çevresel bir takım riskleri ve ekolojik kıtlıkları azaltırken aynı zamanda insanların refahını ve toplumsal eşitliği sağlayan bir ekonomidir (UNEP, 2010: 11-15). Nitekim yeşil ekonomi, çevreyle ilgili riskleri ortadan kaldırmak, sürdürülebilirliği sağlamak ve istihdamı arttırmak üzere, mali, sektörel, ulusal ve uluslararası düzenlemeleri kapsayan bir sistem olarak kabul edilir (Demirtaş, 2012: 2). $\mathrm{Bu}$ tür bir ekonomiye geçiş süreci; ekonomik kalkınma, biyolojik çeşitlilik, ekosistem, iklim değişiklikleri, sağlık ve refah gibi alanlarda orta ve uzun vadede yapılan yatırımları içeren bir dizi aşamayı gerekli kılmaktadır.

Bir ülkenin yeşil ekonomiye geçişinin sağlayacağı bazı avantaj ve dezavantajlar bulunmaktadır. Öyle ki çevreye uyumlu ekonomik malların ortaya çıkması, sürdürülebilir şehirlerde yaşam kalitesinin yüksek oranda artması, enerji ve diğer doğal kaynaklara olan talebin azalması yeşil ekonominin önemli avantajlarıdır. Üretim ve tüketim faaliyetlerinin çevre üzerindeki etkilerinin incelenmesine yönelik ortaya çıkan yeşil ekonominin, göstergeleri bakımından karar alma süreçlerine rehberlik etme ve sürdürülebilir kalkınma göstergelerinde olduğu gibi ekonomi politikalarının belirlenmesi konusunda da faydalı olabileceği ifade edilebilir (Okumuş, 2013: 23). Ancak bu avantajların yanında; enerji ve maden kaynaklarının fiyatlarının artması, dayanıklı ürünlerin üretim maliyetlerinin ve piyasa fiyatlarının yükselmesi, büyük ölçekli işletmelerde işsizliğin artması ve satın alma gücünde azalma gibi bazı dezavantajları da bulunmaktadır (Kuşat, 2013: 4092).

Yeşil ekonomi günümüzde birçok ülke açısından üzerinde odaklanılan temel bir iktisadi hedef niteliği kazanmıştır. Elbette bunun gerçekleşmesinde Birleşmiş Milletler öncül bir rol üstlenmiştir. Nitekim ilk kez 1972 yılında Stockholm Konferansı ile başlayan ve çeşitli aşamalardan geçtikten sonra 1992 yılında Rio'da organize edilen Birleşmiş Milletler Çevre ve Kalkınma Konferansı ile sürdürülebilir kalkınma kavramı çerçevesinde insanlığın ortak kalkınma stratejisinin belirlenmesine yönelik çeşitli adımların atılması hedeflenmiştir (Yayl1, 2012: 161). Bu amaçla Rio+10 ve Rio +20 adıyla iki konferans daha düzenlenmiş ve bu konferanslarda yeşil ekonomiye geçiş ile ilgili olarak kamu ve özel sektör için yol gösterici önerilerin getirilmesi ve bu önerilerin üye ülkeler tarafindan benimsenmesi için zemin hazırlanması öngörülmüştür. Diğer taraftan Dünya Çevre ve Kalkınma Komisyonu'nun 1987 yılında yayınlamış olduğu "Ortak Geleceğimiz" adlı raporda da günümüz insanlarının kalkınma için mevcut kaynakların gelecek kuşakların da kullanacağı kısmına dokunmadan yararlanma yetisine sahip olduğu üzerinde durulmuştur (UNWCED, 1987).
Sürdürülebilir kalkınma olarak ifade edilen bu durumun önemli ölçüde yeşil ekonomi çerçevesinde sağlıklı bir şekilde gelişebileceğini vurgulamak gerekir. Öyle ki sürdürülebilir kalkınma konusundaki çalışmalar; geçmişten bu yana geleneksel ekonomik kalkınma modellerinin oraya çıkardığ 1 çevresel sorunların azaltılmasına yönelik olup, bu amaçla yeşil ekonomi temelli kalkınma modelini destekleyici nitelik taşımaktadır (Carley vd. 2011: 289). Sonuç itibariyle tüm bu çabaların yansıması olarak 2000'li yıllardan itibaren birçok ülkede çevresel sürdürülebilir ekonomik kalkınma modelleri daha fazla vurgulanır hale gelmiştir (Ha, 2011: 7).

\subsection{Türkiye'de \\ Yeşil Ekonomiye \\ Yönelik}

\section{Düzenlemeler}

Birçok ülkede olduğu üzere, Türkiye'de de yeşil ekonomiye geçiş yönünde önemli adımlar atılmıştır. Bu doğrultuda çeşitli kamu kurum ve kuruluşları tarafından bir dizi çalışma yürütülmektedir. Bu tür faaliyetler neticesinde çevresel sorunların giderilmesi ve sürdürülebilir bir sosyoekonomik yaşam tarzının oluşturulması hedeflenmektedir. Bu hedef doğrultusunda özellikle kalkınma planları başat olma özelliği taşımaktadır. Nitekim kalkınma planları Türkiye ekonomisinin yönlendirilmesinde temel çerçeveyi oluşturan; sanayileşmeye, ekonomik ve sosyal kalkınmayı gerçekleştirme yönünde önlemleri ortaya koyan ve devlet politikalarının belirlendiği temel politika belgeleridir (Okumuş, 2013: 34).

Birinci Beş Yıllık Kalkınma Planı (1963-1967), İkinci Beş Yıllık Kalkınma Planı (1968-1972) ve Üçüncü Beş Yıllık Kalkınma Planı'nı (1973-1977) kapsayan ilk üç plan dönemi incelendiği takdirde; 1963-1977 yılları arasını kapsayan dönemde çevre, çevre kirliliği ve çevresel sürdürülebilirlik gibi kavramlara hiç değinilmediği görülmektedir. Bu planları takiben Dördüncü Beş Yıllık Kalkınma Planı (1979-1983) ise çevre konusuna ilk kez atıfta bulunan belge olarak dikkat çekmektedir. Nitekim ilgili planda çevre sorunları başlığı altında; su, hava ve gürültü kirliliği ile toprak erozyonu ve kirlenmesi konuları üzerinde durulmuş ve çevre ile ilgili sorunlardan en önemlisinin toprak aşınması olduğu belirtilmiştir. Buna karşın plan kapsamında çevrenin korunmasına yönelik herhangi bir politik hedefin belirlenmediği de görülmektedir.

Beşinci Beş Yıllık Kalkınma Planı'nı kapsayan dönemde (1985-1989) ülkemizde şehirleşme, erozyon ve tabii afetlerin neden olduğu çevre sorunları ile karşı karşıya kalındığı ifade edilmiştir. Bu planda çevresel sürdürülebilirliğin gerekliliği hususu ilk defa vurgulanmış ve bunun sağlanmasına yönelik kamu kurum ve kuruluşlarının çevre alanında yürütecekleri araştırma ve geliştirme faaliyetlerine öncelik verileceği ifade edilmiştir. Bu planı takiben Altıncı Beş Yıllık Kalkınma Planı'nda ise (1990-1994) çevrenin korunması ve çevre sorunlarının çözüme kavuşturulması gerekliliğine geniş bir şekilde yer verilmiş ve doğal yaşamda meydana gelebilecek olan tahribatların engellenmesi amacıyla üretim aşamasında yenilenebilir enerji kaynaklarının kullanılmasının önemi vurgulanmıştır. Ayrıca toplumda çevre bilincinin oluşturulması için bir dizi çalışmanın yürütülmesinin zaruriyeti üzerinde durulmuştur.

1996 ve 2000 yıllarına ilişkin hazırlanan Yedinci Beş Yıllık Kalkınma Planı'nda çevrenin korunmasına yönelik politikaların belirlenmesi ve ilgili kuruluşlar arasında koordinasyonun sağlanması açısından Çevre Bakanlığı'nın yetersiz kaldığı ve yürürlükteki 2872 sayılı Çevre Kanunu'nun ihtiyaçlara cevap veremediği ifade edilmiştir. 
Öte yandan sürdürülebilir kalkınmanın temel hedef olarak belirlenmiş olmasına rağmen ekonomik ve sosyal kararların alınması sırasında çevrenin ihmal edilmekte olduğu dile getirilmiştir. İlgili planda; sürdürülebilir kalkınma çerçevesinde çevresel sürdürülebilirliğin gerçekleşmesi, çevre dostu teknolojilerin benimsenmesi ve çevre sorunlarının çözümünde $\mathrm{AB}$ normlarına ve uluslararası standartlara uygun bir süreç izlenmesi gerektiği vurgulanmıştır. Ayrıca planın hukuki ve kurumsal düzenlemeler kısmında; 2872 sayılı Çevre Kanunu'nun günün koşullarına göre revize edilmesine, 6831 sayılı Orman Kanunu'nun orman kaynaklarının korunmasına yönelik yeniden düzenlenmesine ve 3194 sayılı İmar Kanunu'nun ise doğal çevrenin planlamasına yönelik revize edilmesine ihtiyaç olduğu ifade edilmiştir.

2001-2005 dönemine ilişkin hazırlanmış olan Sekizinci Beş Yıllık Kalkınma Planı, ilk kez sera gazı emisyonuna değinmesi ve yoğun sera gazı salınımına neden olan sektörlere vurgu yapmış olması açısından ön plana çıkmaktadır. Planda emisyonun kontrol altına alınması gerekliliği üzerinde durulmuş ve enerji verimliliğinin artırılması ve tasarruf sağlanması yönünde düzenlemelere gidileceği belirtilmiştir. Ayrıca planda 2872 sayılı Çevre Kanunu'na ve Çevre Bakanlığının görev ve sorumluluklarına tekrar vurgu yapılmıştır. Dokuzuncu Kalkınma Planı'nda (2007-2013) ise önceki planlardan farklı olarak "kirleten ve kullanan öder yaklaşımı" benimsenmiş, Avrupa Birliği'ne uyum kapsamında çevresel standartlar güncelleştirilmiş ve çevresel altyapı yatırımlarının hızlandırılması gerekliliğine dikkat çekilmiştir.

Halihazırda devam etmekte olan Onuncu Kalkınma Planı'nda (2014-2018) ise yaşanılabilir mekanlar ve sürdürülebilir çevre başlığı altında yer alan alt başlıklar ise bölgesel gelişme ve bölgesel rekabet edilebilirlik, mekansal gelişme ve planlama, kentsel dönüşüm ve konut, kentsel altyapı, mahalli idareler, kırsal kalkınma, çevrenin korunması, toprak ve su kaynaklarının yönetimi, afet yönetimi şeklinde sıralanmaktadır. Nitekim mevcut plan, tüm kalkınma planlarının içinde çevrenin korunması amacına yönelik en kapsamlı plan olma özelliği taşımakta ve planda iktisadi büyümenin özellikle yeşil ekonomiye dayalı büyüme şeklinde gerçekleştirilmesi gerekliliği vurgulanmaktadır. Ayrıca bu hedefe yönelik denetim mekanizmalarının daha güçlü hale getirileceği hususuna da değinilmektedir.

Ülkemizdeki kalkınma planlarının yanı sıra mevcut anayasamızın da çevre konusuna atıf yaptığını belirtmek gerekmektedir. Nitekim 1982 Anayasası'nın 56. maddesine göre; “ Herkes sağllklı bir çevrede yaşama hakkına sahiptir. Çevreyi geliştirmek, çevre să̆lı̆̆ını korumak ve çevre kirlenmesini önlemek Devletin ve vatandaşların ödevidir." ifadesi yer almaktadır. 1982 Anayasası'ndaki çevre ile ilgili yer alan bu madde ile ilk kez bir Türk Anayasası'nda çevre hakkından söz edilmiş ve çevrenin korunması devletin sorumluluğu, bireyin sorumluluğu ve bireyin hakkı olmak üzere üç yönden ele alınmıştır (Bozkurt, 2010: 23). Yine anayasanın 43. maddesinde kıyılardan yararlanılması; 44. maddesinde toprağın korunmasi; 45.maddesinde tarih, kültür ve tabiat varlıklarının korunması; 63. maddesinde tabii servetler ve kaynakların korunması ve 168. maddesinde ormanların korunması ve geliştirilmesi amaç ve hedef olarak ortaya konulmaktadır (Karacan, 2012: 660).

Çevre konusuna doğrudan veya dolaylı vurgu yapan çeşitli kanun ve yönetmelikler de mevcuttur. Nitekim kanun olarak; Çevre Kanunu, Kültür ve Tabiat Varlıklarını Koruma
Kanunu, Boğaziçi Kanunu, Milli Parklar Kanunu, İmar Kanunu, Kıyı Kanunu, Sular Hakkında Kanun, Yer Altı Suları Hakkında Kanun, Su Ürünleri Kanunu, Sulak Alanlar ve Kara Avcılığı Kanunu, Tarım, Orman ve Köy Hizmetleri Kanunları, Orman Kanunu, Turizmi Teşvik Kanunu, Genel Sağlığı Koruma Kanunu, Hayvanları Koruma Kanunu sayılabilir (Karacan, 2012: 660-661). İlgili yönetmelikler arasında ise; Hava Kalitesi Kontrol Yönetmeliği, Ozon Tabakasını İncelten Maddelerin Azaltılmasına İlişkin Yönetmelik, Kirliliğin Önlenmesi Fonu Yönetmeliği, Kıyı Kanununun Uygulanmasina Dair Yönetmelik, Toprak Kirliliğini Kontrol Yönetmeliği, Tarımsal Alanların Tarım Dışı Amaçlarda Kullanımına İlişsin Yönetmelik, Katı Atıkların Kontrolü Yönetmeliği, Zehirli Kimyasallar Yönetmeliği, Tehlikeli Atıkların Kontrolü Yönetmeliği, Tıbbi Atıkların Kontrolü Yönetmeliği, Radyasyon Güvenliği Yönetmeliği, Radyoaktif Madde Kullanımından Oluşan Atıklara İlişkin Yönetmelik, Gürültü Kontrol Yönetmeliği, Çevresel Etki Değerlendirmesi Yönetmeliği ile Atık Piller ve Akümülatörlerin Kontrolü Yönetmeliği dikkat çekmektedir.

\section{Yenilenebilir Enerji Türü Olarak Rüzgar Enerjisi} ve Dünyada Yaygınlaşma Düzeyi

"Yaşanabilir bir dünya" belki de çocuklarımıza bırakabileceğimiz en önemli mirastır. Bunun için günümüz sosyo-ekonomik hayatımızı ve elbette üretimimizi bu hedefe uygun şekillendirmek zorundayız. Yeşil ekonomi kapsamında değerlendirilen çevreyle barışık bir üretim modelini tesis edebilmek için yenilenebilir enerji kaynakları en önemli unsurlardır. Bunlar içinde rüzgar enerjisi ön plana çıkan kaynaklardan biri olup, bu kaynak dünya döndükçe yani yaşam var oldukça hep potansiyel bir enerji kaynağı olma misyonunu sürdürecektir. Nitekim bu kısımda rüzgar enerjisi kavramı, çeşitli ülkelerdeki rüzgar enerjisi potansiyeli ve kullanım kapasitesi üzerinde durulacaktır.

\subsection{Rüzgar Enerjisi Kavramı}

Güneş enerjisinin karaları, denizleri ve atmosferi her yerde aynı derecede 1sıtmamasından dolayı ortaya çıkan sıcaklık ve basınç farkları rüzgarı ortaya çıkarmaktadır. Öyle ki rüzgar enerjisinin varlığı için güneş enerjisinin var olması gereklidir. Çünkü güneş enerjisi, rüzgar enerjisinin dolaylı bir ürünüdür (T.C. Güney Ege Kalkınma Ajansı, 2012: 17). Güneşten gelen 1şınlar dünya atmosferinde 1sınmaya sebep olur ve 1sınarak yoğunluğu azalan hava yükseldiği için bu havanın yerini soğuk hava doldurur. Bu hava dünyanın kendi etrafinda dönme hareketiyle birleştiğinden dolayı yüksek oranda kinetik enerji taşıyan hava hareketleri ortaya çıkar (http://www.alternaturk.org/ruzgar.php.,e.t. 29.10.2014). Rüzgar enerjisi ise hava kitlesinin sahip olduğu kinetik enerjinin mekanik enerjiye dönüşmesi neticesinde oluşur. Yani rüzgar enerjisi, dönüşüme uğramış güneş enerjisi olarak da nitelendirilmekte ve dünyaya ulaşan güneş enerjisinin yaklaşık olarak \%2'si rüzgar enerjisine dönüşmektedir (http://www.enerji.gov.tr/tr-TR/Sayfalar/Ruzgar,

\section{E.T:30/10/2014)}

Rüzgar enerjisi, yenilenebilir enerji kaynağı olmakla birlikte çevre üzerindeki olumsuz etkisi neredeyse yok denecek kadar az düzeyde ve yeşil çevre dostu olan bir enerji kaynağıdır. Fosil yakıtların kullanılması suretiyle elektrik enerjisinin üretilmesi sonucunda çevreye verilen zararın büyüklüğü, rüzgar enerjisinin kullanılması durumuna göre oldukça fazladır. Çünkü yakıtı rüzgar olan rüzgar türbinleri, 
fosil yakıtların aksine atmosfere zehirli gaz salınımına yol açmamaktadır (Aydın, 2013: 33).

Rüzgar enerjisinin diğer enerji türleriyle karşılaştırılması yapıldığında yatırım ve birim enerji maliyeti açısından rüzgar enerjisinin çok avantajlı bir enerji türü olduğu ortaya çıkmaktadır.

Tablo 1: Enerji Türlerinin Yatırım ve Birim Maliyet Karşı1laştırması

\begin{tabular}{lcc}
\hline \multicolumn{1}{c}{ Enerji Türü } & $\begin{array}{c}\text { Yatırım } \\
\text { Bedeli(\$/kW) }\end{array}$ & $\begin{array}{c}\text { Birim Enerji } \\
\text { Maliyeti(cent/kWh) }\end{array}$ \\
\hline Petrol & $1500-2000$ & 6 \\
Kömür & $1400-1600$ & $2,5-3$ \\
Doğalgaz & $600-700$ & 3 \\
Nükleer & $3000-4000$ & 7.5 \\
Hidrolik & $750-1200$ & $0.5-2$ \\
Güneş & Yüksek & $10-20$ \\
Jeotermal & $1500-2000$ & $2.2-4$ \\
Rüzgar & $1000-1200$ & $3,5-4,5$ \\
\hline
\end{tabular}

Kaynak: www.yildiz.edu.tr/ zyumur/duyurular.../

ekoteknolojiler \%20sunumu.ppt. (erişim:01.04.2015)

Rüzgar enerjisinin bir ülkeye sağlayabileceği bazı avantajlar ve dezavantajlar bulunmaktadır. Rüzgar santrallerinin kullanılmasının çevreye yönelik sağlamış olduğu avantajlar; yakıt masraflarının ve hammadde ihtiyaçlarının olmaması, temiz enerji kaynağı olma özelliği taşıması sebebiyle çevreye olan zararının çok az olması, tükenmeyen yenilenebilir enerji kaynağı özelliğine sahip olması, diğer santrallere göre daha kısa sürede kurulum özelliğine sahip olması, fosil yakıtlarda olduğu gibi sera gazı etkisine sahip olmaması, ömrü dolan türbinlerin sökülerek yerine yenisinin takılmasının söz konusu olabilmesi şeklinde sıralanabilir (Acar ve Doğan, 2008: 680). Bunun yanında rüzgar santrallerinin kullanılmasının, fosil yakıtların yanması sonucu zararlı gazların oluşmasını engelleyerek, sera etkisi ve asit yağmurlarına yol açmaması, türbinlerin 20-30 yıl gibi uzun süre kullanılabilmesi ve böylece maliyetlerin uzun bir zamana yayılmasının sağlanması, türbin, kanat ve diğer parça üreticileri, üretilen elektriğin satış ve dağıtımını gerçekleştiren işletmeler, uzmanlık, danışmanlık, ve mühendislik gerektiren Ar-Ge, montaj-servis-bakım, finans, pazarlama ve birçok alanda teknik ve idari iş alanlarında istihdam imkanı sunarak gerek ekonomik, gerekse sosyal gelişime katkıda bulunması şeklinde faydaları vardır (Bayraç, 2011: 40-41). Bu avantajlara sahip ve bölgeye özgü enerji kaynağı olarak kabul edilen rüzgar enerjisi, coğrafi ve meteorolojik engellerin bulunmasına rağmen, sürekli bir kaynak olması özelliğinden dolayı sürdürülebilir kalkınmanın sağlanmasında önemli bir role sahiptir (Koçaslan, 2010: 5657).

Rüzgar enerjisinin dezavantajları; gürültüye sebep olması, kuşların rüzgar türbinlerine sürüklenerek ölmesi ile habitat ve doğal yaşama yönelik bazı etkilerinin olması, çevredeki radyo ve TV alıcılarında parazitlenmeye sebep olarak elektromanyetik alana etkide bulunması, özellikle yaşam alanlarına yakın olan yerlere kurulmasının görsel açıdan göze hoş gelmemesi şeklinde ifade edilebilir. (Karataş, 2009: 7678). Bunlarla birlikte rüzgar santrallerinin kurulumu için gerekli olan teçhizatın büyük bir bölümünün ithal edilmek suretiyle temin edilmesi türbinlerin kuruluş maliyetlerinin artmasına neden olur. Ayrıca rüzgar hızının değişken olmasından dolayı istenilen her bölgeye rüzgar santralinin kurulmasının mümkün olmaması gibi dezavantajlar sıralanabilir. (Bayraç, 2011: 41-42). Bu tür dezavantajlara rağmen özellikle çevreye verdiği zararın nispeten az olması ve bir çok avantajının bulunması nedeniyle rüzgar enerjisinin tüm dünyada enerji üretimi için kullanımı hızlı bir şekilde artmaktadır. Nitekim rüzgar enerjisi tabanlı sistemlerin düşük işletme maliyetleri söz konusu olmakta ve yatırımların geri dönüşüm süreleri yaklaşık 10 yılı bulmaktadır. Rüzgar güllerinin ortalama ömrü ise 25 yıl olup, bu yönüyle rüzgar enerjisi yatırım yapılması oldukça verimli kabul edilen bir enerji türü olarak nitelendirilmektedir (http://www.emo.org.tr/ekler/ f03c8237bf6d4ab_ek.pdf).

\section{2.Çeşitli Ülkelerde Rüzgar Enerjisi Kapasiteleri ve Kullanım Oranları}

Tarihte ilk defa 1891 yılında Danimarka'da rüzgar enerjisinden elektrik üretimi gerçekleştirilmiş olup, daha sonra Amerika Birleşik Devletleri'nde de yel değirmenlerinden enerji üretimine başlanmıştır. Ancak rüzgar enerjisi, 1990'lı yıllardan itibaren en hızlı yaygınlaşan enerji kaynağ1 olmuştur (Oskay, 2014: 80). Özellikle bu dönemde artan çevre kirliliğinin dünya açısından önemli etkilere yol açması ve bu duruma neden olarak temelde fosil yakıtların gösterilmesi yenilenebilir enerji kaynaklarına yönelimi hızlandırmıştır. Nitekim 1996 yılında tüm dünyada sadece 6100 MW'lık bir rüzgar enerjisi üretimi söz konusuyken, 2013 yılına gelindiğinde bu rakamın 318.105 MW'a ulaşması bu konuya verilen önemin yansımasıdır. Sadece 18 yılda rüzgar enerjisi kullanım kapasitesi 52 kat artış göstermiştir ki bu da yıllık yaklaşık 2,9 kat artış demektir. Öte yandan 2050 yılı itibariyle dünyadaki enerji tüketiminin kötümser tahminle $\%$ 11'i, iyimser tahminle yaklaşı \% 26'sı ve ortalama beklentilerde ise \% 17'sinin rüzgar enerjisinden karşılanacağı öngörülmektedir (Global Wind Outlook, 2014: 56). Bu tür bir beklenti dahi rüzgar enerjisinin sürekli artan enerji ihtiyacını karşılama açısından giderek daha fazla öneme sahip olduğunu vurgular niteliktedir. 
A. Özen, M. Ü. Şaşmaz, E. Bahtiyar / KMÜ Sosyal ve Ekonomik Araştırmalar Dergisi 17 (28): 85-93, 2015

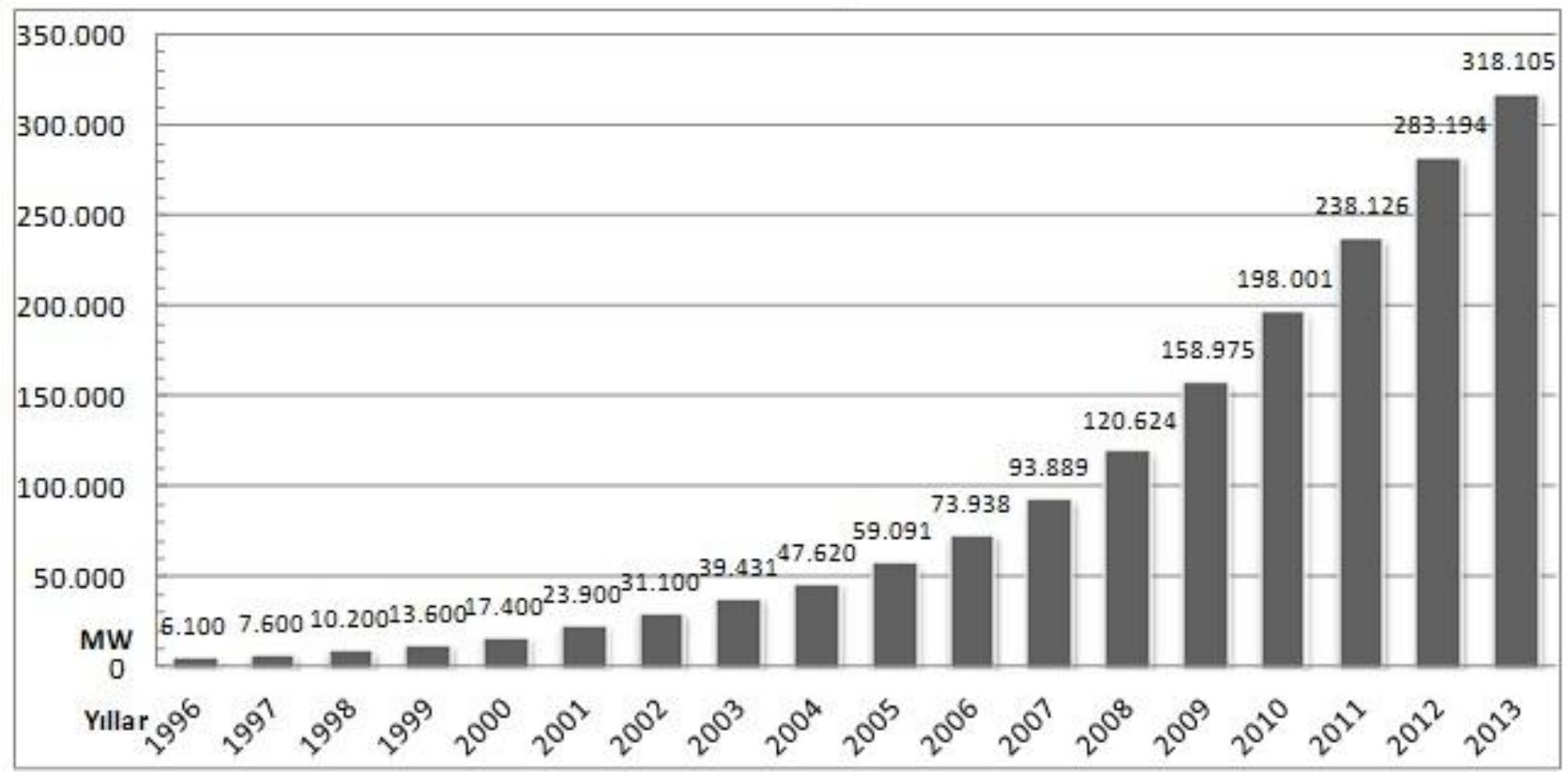

Kaynak:http://www.gwec.net/wp-content/uploads/2014/04/6_21-2_global-cumulative-installed-wind-capacity-1996-2013.jpg

Şekil 1: Küresel Kurulu Rüzgar Gücü Kapasitesi-MW (Kümülatif)

Mevcut durum dikkate alındığında Çin'in, rüzgar enerjisi kullanımı açısından dünyada ilk sırada yer aldığı görülmektedir. Çin ile birlikte Amerika Birleşik Devletleri ve Almanya başı çeken ülkeler arasında yer almaktadır. 2014 yılı başı itibariyle dünyada 1000 MW'den fazla üretim kapasitesi olan ülke sayısı 24'e ulaşmıştır. Bunların 16'sı Avrupa'da, 4'ü Asya-Pasifik grubunda, 3'ü ise Kuzey Amerika'da ve 1'i ise Latin Amerika'da bulunmaktadır. Bu ülkelerden Çin, Amerika Birleşik Devletleri, Almanya,
İspanya, Hindistan ve İngiltere ise $10.000 \mathrm{MW}$ 'dan fazla üretim kapasitesine sahip ülkeler olarak dikkat çekmektedir (GWEC, 2013: 16). Türkiye ise $2958 \mathrm{MW}$ 'lı kurulu gücü ile dünyadaki toplam üretim kapasitesinin yaklaşık \%1'lik kısmına sahiptir (Bkz Tablo 2). Elbette bu durum ülkemiz açısından atılması gereken pek çok adımın olduğunu ortaya koymaktadır.

Tablo 2: Kurulu Rüzgar Gücüne Göre Ülkelerin Enerji Üretim Potansiyeli ve Pazar Payları (2013)

\begin{tabular}{ccc} 
Ülkeler & MW & Küresel Pazar Payı (\%) \\
\hline Çin & 91,412 & 28.7 \\
ABD & 61,091 & 19.2 \\
Almanya & 34,250 & 10.8 \\
İspanya & 22,959 & 7.2 \\
Hindistan & 20,150 & 6.3 \\
İngiltere & 10,531 & 3.3 \\
İtalya & 8,552 & 2.7 \\
Fransa & 8,254 & 2.6 \\
Kanada & 7,803 & 2.5 \\
Danimarka & 4,772 & 1.5 \\
Türkiye & 2,958 & 0,93 \\
Diğer Ülkeler & 48,332 & 15.2 \\
\hline Dünya Toplamı & 318,105 & 100
\end{tabular}

Kaynak: Global Wind Energy Council, Global Wind Report Annual Market Update 2013, s.18'den yararlanarak hazırlanmıştır.

\section{Türkiye'de Rüzgar Enerjisi Potansiyeli ve}

\section{Destekleyici Teşvik Politikaları}

İthalatının önemli bir kısmının enerji ve türevlerinden oluştuğu Türkiye, enerjiyi ithal eden ülkeler sınıfinda yer almaktadır. Öyle ki enerjide dışa bağımlılık, ülkemizi hem kur risklerine hem de enerji fiyatlarında yaşanacak şoklara karşı korumasız kılabilmektedir. Bu durum; kalkınma yolunda olan ülkemiz açısından plan ve programlama sürecinde bazı belirsizliklerin yaşanabilmesi açısından sorun teşkil edebilmektedir. Ayrıca ülkemizde 2014 yılı itibariyle kişi başına GSYH 10.4040,1 ABD doları şeklinde gerçekleşmiş olup, bu sonuçla orta gelir tuzağında yer alan bir ülke olarak ifade edilebilir. Ülkemizin 10.000-20.000 ABD Doları arasında kabul edilen bu tuzaktan çıkabilmesi için enerji ihtiyacında dışa bağımlılığı azaltması temel bir hedef olarak görülmektedir. İşte bu hedefi destekleyici olması 
açısından da rüzgar enerjisi; hem kalkınma hem de çevresel olumlu dışsallıklarının yüksek olmasından dolayı son yıllarda artan bir gelişim göstermektedir.

$\mathrm{Bu}$ kısımda öncelikle ülkemiz açısından rüzgar enerjisi potansiyeli ve kullanım kapasitesi üzerinde durulacak ve mevcut kapasitenin arttırılmasına yönelik teşvik politikaları hakkında bilgilere yer verilecektir.

\subsection{Türkiye'de Rüzgar Enerjisi Kapasitesi ve} Kullanım Düzeyi

Türkiye, rüzgar enerjisi açısından hatırı sayılır bir düzeyde potansiyele sahip bir ülkedir. Nitekim Türkiye'de yer seviyesinden 50 metre yükseklikte ve $7.5 \mathrm{~m} / \mathrm{s}$ üzeri rüzgar hızına sahip alanlarda kilometrekare başına $5 \mathrm{MW}$ gücünde rüzgar santrallerinin tesis edilmesi kabul edilebilir durumdadır. $\mathrm{Bu}$ bağlamda ülkemizin rüzgar enerjisi potansiyeli de 48.000 MW olarak belirlenmiştir (http://www.eie.gov.tr/eieweb/turkce/YEK/ruzgar/ruzgar_en_ hak.html). Bu potansiyelin iktisadi açıdan anlamı ise şu şekilde ortaya konulabilir: 1 varil petrol $775 \mathrm{KWh}$ enerji ürettiğine göre, 48.000 MW'lık rüzgar enerjisi 61935 varil petrole eş değerdedir. 2015 Nisan (08.04.2015 tarihinde) ayı başı itibariyle 1 varil petrol 58 ABD Doları civarında olup, rüzgar enerjisi potansiyelinin ekonomik değeri yaklaşık 3,6 milyar ABD Dolarına eş değerdedir. Böylece rüzgar enerjisinin etkin şekilde kullanımının yıllık 3,6 milyar ABD Dolarlık bir kaynağın ülkemizde kalmasını sağlayacağı ifade edilebilir.

Türkiye'nin coğrafi özelliklerine bakıldığında, rüzgar enerjisinin önemli bir enerji kaynağı olduğu söylenebilir. TC Enerji ve Tabii Kaynaklar Bakanlığı'na bağlı Yenilenebilir Enerji Genel Müdürlüğü tarafindan yapılan ölçümlerde Marmara, Güneydoğu Anadolu ve Ege Bölgelerinin rüzgar gücü açısından diğer bölgelerle göre daha zengin olduğu tespit edilmiştir. Özellikle Çanakkale-Balıkesir, Manisa-İzmir ve Hatay bölgeleri bu açıdan ön plana çıkmaktadır.

Türkiye'de rüzgar enerjisinden elektrik elde etme amacına yönelik çalışmalar 1986 yılından itibaren başlamış ve ilk rüzgar santrali 1986 yılında Çeşme Altınyunus tesisinde kurulmuştur. Uluslararası düzeyde ilk rüzgar enerjisi santrali ise yine Çeşme'de, Germiyan köyünde 1998 yılında kurulmuştur (Oskay, 2014: 85). Günümüz itibariyle ülkemizde toplam 1600 MW kurulucu gücü olan 1000'den fazla rüzgar santrali bulunmaktadır. Rüzgar enerjisinin büyümesi yönünden ülkemiz Avrupa'da önde gelen 10 ülkeden biri olup, toplam da $8000 \mathrm{MW}$ lisans almış ve inşaat aşamasinda santral söz konusudur (http://www.elektrikport.com/teknik-kutupha ne /2023yolunda -turkiyenin-yenilenebilir-enerji-hedefleri/8167 \#adimage-0). Nitekim Küresel Rüzgar Enerjisi Konseyi (GWEC) tarafindan her y1l yayınlanan rapora göre Türkiye'nin 2013 yılında da büyüyen bir rüzgar enerjisi piyasasının olduğu ve 2,959 MW'lık toplam üretimin bulunduğu ifade edilmiştir. Ayrıca bunun 646 MW'lık kısmı 2013 yılından itibaren elde edilmeye başlanmıştır. İlgili raporda üretimde artan bu ivme ile Türkiye'deki rüzgar enerjisi sektörünün geleceğinin oldukça parlak olduğu vurgulanmıştır (GWEC, 2013: 23). Bu gelişmeler 1şığında 2015 yılı itibariyle ülkemizde üretilen elektriğin \% 5'nin rüzgar enerjisinden elde edileceği tahmin edilmektedir (Ata, 2010: 50-51). Dönemin siyasi karar alıcıları tarafından hazırlanmış olan Elektrik Enerjisi Piyasası ve Arz Güvenliği Strateji Belgesi'ne göre ise 2023 yılında yenilenebilir enerjiye dayalı olarak üretilen elektriğin tüm elektrik üretim portföyündeki ağırlığının \% 30 düzeyine gelmesi ve rüzgar enerjisine dayalı kurulu gücün en az 20.000 MW olması hedeflenmektedir (http://www.enerji.gov.tr/File/?path=ROO

T\%2F1\%2FDocuments\%2FBelge\%2FArz_Guvenligi_Stratej i_Belgesi .pdf).

Tablo 3: Mevcut Düzenlemeler ve TÜREY Önerileri ile Yapılacak Kurulu Güç Miktarı

\begin{tabular}{|c|c|c|c|c|c|}
\hline \multirow[t]{2}{*}{ Yillar } & \multirow{2}{*}{$\begin{array}{c}\text { Mevcut } \\
\text { Düzenlemeler İle } \\
\text { Yapılacak Kurulu } \\
\text { Güç (MW) Yıllık }\end{array}$} & \multicolumn{2}{|c|}{$\begin{array}{l}\text { TÜREY Önerileri ile Yapılacak } \\
\text { Kurulu Güç MW (Yıllık) }\end{array}$} & \multirow{2}{*}{$\begin{array}{c}\text { Mevcut } \\
\text { Düzenlemeler } \\
\text { İle Kurulu Güç } \\
\text { MW } \\
\text { (Kümülatif) }\end{array}$} & \multirow{2}{*}{$\begin{array}{l}\text { TÜREY Önerileri ile } \\
\text { Kurulu Güç MW } \\
\text { (Kümülatif) }\end{array}$} \\
\hline & & $\begin{array}{c}\text { Yabancı } \\
\text { Üretim }\end{array}$ & Yerli Üretim & & \\
\hline 2012 & - & - & - & 2300 & - \\
\hline 2013 & 620 & 580 & - & 2920 & 3500 \\
\hline 2014 & 740 & 760 & - & 3660 & 5000 \\
\hline 2015 & 820 & 680 & - & 4480 & 6500 \\
\hline 2016 & 780 & 720 & 100 & 5260 & 8100 \\
\hline 2017 & 810 & 690 & 100 & 6070 & 9070 \\
\hline 2018 & 790 & 710 & 200 & 6860 & 11400 \\
\hline 2019 & 680 & 720 & 200 & 7540 & 13000 \\
\hline 2020 & 720 & 680 & 300 & 8260 & 14700 \\
\hline 2021 & 840 & 560 & 300 & 9100 & 16400 \\
\hline 2022 & 750 & 650 & 400 & 9850 & 18200 \\
\hline 2023 & 770 & 630 & 400 & 10620 & 20000 \\
\hline
\end{tabular}

Kaynak: Türkiye Rüzgar Enerjisi Birliği, “Türkiye Rüzgar Enerjisi Yol Haritası”, Kasım 2012, İstanbul, s.27.

Türkiye'de rüzgar enerjine yönelik 2005 yılında yürürlüğe giren Yenilenebilir Enerji Kaynaklarının Elektrik Enerjisi Üretimi Amaçlı Kullanımına İlişkin Kanun ve 6094 Sayılı Yenilenebilir Enerji Kaynaklarının Elektrik Enerjisi Üretimi Amaçlı Kullanımına İlişkin Kanun kapsamında sürdürülen teşvik politikalarının yansıması Tablo 4'de net olarak görülmektedir. Tablo incelendiğinde özellikle 2005 yılını takiben rüzgar enerji üretim potansiyelinin sürekli artış gösterdiği söylenebilir. Öyle ki ülkemizde 2005 yılı itibariyle toplam 20,1 MW'lık bir kurulu güç bulunmaktayken, 2006 yılından başlayarak bunun her yıl hızla arttığı ve 2014 yılı Temmuz ayı itibariyle 3424,4 MW'a ulaştı̆ğ görülmektedir. $\mathrm{Bu}$ gelişme geleceğe daha iyimser bakılmasını sağlar nitelikte olsa da dünya geneli itibariyle henüz ülkemizin atması 
A. Özen, M. Ü. Şaşmaz, E. Bahtiyar / KMÜ Sosyal ve Ekonomik Araştırmalar Dergisi 17 (28): 85-93, 2015

gereken daha çok adımın olduğu da vurgulanmalıdır (Bkz Tablo 2).

Tablo 4: Türkiye'de Rüzgar Enerjisi Yatırımlarının Kurulu Güç Bakımından Dağılımı ve Kümülatif Değeri (MW)

\begin{tabular}{ccc}
\hline Yıllar & $\begin{array}{c}\text { Türkiye'de Res'nin Kurulu Güç Bak. } \\
\text { Dağılımı }\end{array}$ & Türkiye'de Res'nin Kurulu Güç Bak. Küm Değeri \\
\hline 1998 & 8,7 & 8,7 \\
1999 & 0 & 8,7 \\
2000 & 10,2 & 18,9 \\
2001 & 0 & 18,9 \\
2002 & 0 & 18,9 \\
2003 & 1,2 & 20,1 \\
2004 & 0 & 20,1 \\
2005 & 0 & 20,1 \\
2006 & 30,9 & 51 \\
2007 & 95,3 & 146,3 \\
2008 & 217,4 & 363,7 \\
2009 & 427,9 & 791,6 \\
2010 & 537,55 & 1329,15 \\
2011 & 476,7 & 1805,85 \\
2012 & 506,3 & 2312,15 \\
2013 & 646,3 & 2958,45 \\
2014 & 465,95 & 3424,4 \\
\hline
\end{tabular}

Kaynak:Türkiye Rüzgar Enerjisi Birliği, 2014: 4-5

\subsection{Türkiye'de Rüzgar Enerjisine Yönelik Mevcut Teşvikler}

Türkiye'de enerjide dışa bağımlılığı azaltmak ve çevreyle uyumlu bir iktisadi kalkınma gerçekleştirilmek amacıyla yenilenebilir enerji kaynaklarının teşvikine yönelik çeşitli teşvik politikaları uygulamaya konulmuştur. Nitekim 10 Mayıs 2005 tarihli ve 5346 sayılı Yenilenebilir Enerji Kaynakları Kanunu Türkiye'de bu konuyla ilgili ilk yasal düzenleme olarak dikkat çekmektedir. Ayrıca 2007 yılında çıkarılan 5627 sayılı Enerji Verimliliği Kanunu ve 2008 yılında 5784 sayılı Elektrik Piyasası Kanunu'nda değişiklik ile yenilebilir enerji kaynaklarına verilen teşvikler daha da artırılmıştır (Uluatam, 2010: 40).

5346 Sayılı Kanun ile rüzgar enerjisi üretiminde ciddi artışlar meydana gelmiştir. Ancak belirlenen teşviklerin daha da arttırılması amaciyla Enerji ve Tabii Kaynaklar Bakanlığı'nca 5346 sayılı kanunda bazı değişiklikler ve eklemelerin önerildiği kanun tasarısı hazırlanmış ve 6094 sayılı Yenilenebilir Enerji Kaynaklarının Elektrik Enerjisi Üretimi Amaçlı Kullanımına İlişkin Kanunda Değişiklik
Yapılmasına dair Kanun 8 Ocak 2011 tarihinde resmi gazetede yayımlanarak yürürlüğe girmiştir (Oskay, 2014: 8889). İlgili kanuna göre rüzgar enerjisine yönelik teşvikler şu şekildedir:

-Rüzgardan elde edilen elektriğe teşvik alım fiyatı 7.3 dolar cent/kwhdir.

-31/12/2015 tarihine kadar işletmeye giren Rüzgar Enerjisi Santralleri (RES)'lerin yurt içinde gerçekleşen imalatına 5 yıl süreyle yerli katkı ilavesi sağlanacaktır. $\mathrm{Bu}$ ilaveler şu şekildedir: Rüzgar enerjisine dayalı üretim tesisi kanat 0.8 , jeneratör ve güç elektroniği 1.0 , türbin kulesi 0.6 , rotor ve nasel gruplarındaki mekanik aksamın tamamı(kanat grubu ile jeneratör ve güç elektroniği için yapılan ödemeler hariç) 1,3 dolar cent/kwh teşvik verilmektedir. Tablo 5'de görüleceği üzere rüzgar enerjisi üretimine uygulanacak fiyatlar $\mathrm{ABD}$ doları türünden belirlenmiş farklı bölümler için farklı fiyat teşvikleri uygulanmaktadır.

Tablo 5: Rüzgar Enerjisi Üretimine Uygulanacak Fiyatlar

\begin{tabular}{|c|c|c|c|}
\hline \multicolumn{4}{|c|}{ I SAYILI CETVEL } \\
\hline \multicolumn{2}{|c|}{$\begin{array}{l}\text { Yenilenebilir Enerji Kaynağına Dayalı Üretim Tesis } \\
\text { Tipi }\end{array}$} & \multicolumn{2}{|c|}{$\begin{array}{l}\text { Uygulanacak Fiyatlar } \\
\text { (ABD Doları cent/kWh) }\end{array}$} \\
\hline \multicolumn{2}{|c|}{ Rüzgar Enerjisine Dayalı Üretim Tesisi } & \multicolumn{2}{|c|}{7,3} \\
\hline \multicolumn{4}{|c|}{ II SAYILI CETVEL } \\
\hline Tesis Tipi & Yurt İçind & & $\begin{array}{c}\text { Yerli Katkı İlavesi } \\
\text { (ABD Doları cent } / \mathbf{k W h})\end{array}$ \\
\hline \multirow[b]{4}{*}{$\begin{array}{c}\text { Rüzgar Enerjisine } \\
\text { Dayalı Üretim Tesisi }\end{array}$} & & & 0,8 \\
\hline & Jeneratör & & 1,0 \\
\hline & & & 0,6 \\
\hline & \multicolumn{2}{|c|}{$\begin{array}{l}\text { Rotor ve nasel gruplarındaki mekanik aksamın } \\
\text { tamamı(Kanat grubu ile jeneratör ve güç } \\
\text { elektroniği için yapılan ödemeler hariç.) }\end{array}$} & 1,3 \\
\hline
\end{tabular}

Kaynak: 6094 Sayılı Yenilenebilir Enerji Kaynaklarının Elektrik Enerjisi Üretimi Amaçlı Kullanımına İlişkin Kanunda Değişiklik Yapılmasına Dair Kanundan Yararlanılarak Hazırlanmıştır 
$-31 / 12 / 2015$ tarihine kadar yenilenebilir enerji kaynaklarına dayalı üretim tesislerinden, ulaşım yollarından ve lisanslarında belirtilen sisteme bağlantı noktasına kadar ki TEİAŞ ve dağıtım şirketlerine devredilecek olanlar da dahil enerji nakil hatlarından yatırım ve işletme dönemlerinin ilk on yılında izin, kira, irtifa hakkı ve kullanma izni bedellerine $\% 85$ indirim uygulanır.

-31/12/2015 tarihine kadar işletmeye girmiş veya girecek YEK Destekleme Mekanizmasına tabi üretim lisansı sahipleri için rüzgardan elde edilen elektriğe teşvik alım fiyatı on yıl boyunca 7.3 dolar cent/kwh olarak belirlenmiştir. Milli park, tabiat parkı, tabiat anıtı ile tabiatı koruma alanlarında, muhafaza ormanlarında, yaban hayatı geliştirme sahalarında yenilenebilir enerji kaynaklarına dayalı elektrik tesislerinin kurulmasına izin verilir.

-Yenilenebilir enerji kaynaklarına dayalı ve 31/12/2015 tarihinden önce işletmeye giren üretim tesislerinde kullanılan mekanik ve/veya elektro-mekanik aksamın yurt içinde ihmal edilmiş olması halinde; bu tesislerde üretilerek iletim veya dağıtım sistemine verilen elektrik enerjisi için beş yıl süreyle; bu Kanuna ekli II sayılı Cetvelde belirtilen fiyatlar ilave edilir.

-Kanun'da belirlenmiş olan teşvikli fiyatlardan faydalanabilmek için Yenilenebilir Enerji Kaynağı (YEK) belgesine sahip olmakla birlikte YEK destekleme mekanizmasına dahil olmak gereklidir (Altuntaşoğlu, 2011: 60). YEK Destekleme Mekanizmasına bir sonraki takvim yılında tabi olmak isteyenler YEK Belgesi almak ve 31 Ekim tarihine kadar EPDK'ya başvurmak zorunda olmakla birlikte bu mekanizmaya sahip olanlar uygulamaya dahil oldukları yıl içerisinde uygulamadan çıkamazlar.

-YEK Destekleme Mekanizmasına tabi olanların her biri tarafından iletim veya dağıtım sistemine verilen elektrik enerjisi miktarı ile YEK listesindeki fiyatların çarpılması şeklinde enerjinin sisteme verildiği tarihteki Türkiye Cumhuriyet Merkez Bankası döviz alış kuru üzerinden Türk Lirası olarak bedel hesaplanarak teşvik verilir.

\section{Değerlendirme ve Sonuç}

Geleceğin ekonomik yapısını tamamıyla şekillendirmesi öngörülen yeşil ekonominin temel dinamiklerinden biri rüzgar enerjisidir. Fosil yakıtların aksine çevreye verebileceği zarar çok daha az olan bir enerji türü olarak rüzgar, sürdürülebilir kalkınmaya yönelen tüm ekonomiler açısından önem arz etmektedir. Nitekim tüm dünyada özellikle 1990'lı yılların ortasından itibaren çok hızlı ilerleme göstermiş olan rüzgar enerjisi alanında ülkemiz de mevcut potansiyelini kullanma yönünde önemli adımlar atmaktadır. Bu tür adımlar 2023 hedefine yönelen ülkemiz açısından rüzgar enerjisini ön plana çıkarmaktadır. Öyle ki 2023 yılında toplam enerji ihtiyacının \% 30'unu yenilenebilir enerji kaynaklarından karşılamayı hedefleyen ülkemiz açısından rüzgar enerjisine yönelik yatırımların desteklenmesi gereklilik arz etmektedir. Bu amaçla 5346 sayılı Kanunda 2011 yılında ciddi değişiklikler yapılmış ve rüzgar enerjisini destekleyici önemli teşvikler getirilmiştir. Elbette yatırımcılar açısından bu tür teşvikler önemli bir belirleyici olmakta ve 2023 yılındaki 20.000 MW'lık rüzgar enerjisi hedefine yönelik önemli bir basamak niteliği taşımaktadır. Ancak yatırımcıların desteklenmesi açısından çeşitli adımların da atılması sürecin daha hızlı ilerlemesini sağlayabilecektir. Bu hedefle;

$>$ Rüzgar enerjisine yönelik mevcut teşviklerin süreleri 2023 hedefine uygun olacak şekilde belirlenebilir.
> Rüzgar üretimi için elverişli olan bölgelerde yatırımcıların doğru projeksiyon yapabilecekleri veri sistemlerinin kurulması sağlanmalıdır. Böylece firmalar açısından yatırımın geri dönüş süresi ve verimliliği daha anlamlı şekilde bulunabilir.

$>$ Rüzgar santrallerinin kurulmasının çevreye olumsuz etkilerinin söz konusu olabileceği bazı doğal yaşam alanlarında rüzgar enerjisi santrali kurulması gerekmeyebilir. Aksi halde kamuoyu nezdinde rüzgarın doğayla barışık bir enerji kaynağı olduğu yönündeki imajı zedelenebilir ve 2023 hedeflerinden sapılabilir.

> Rüzgar enerjisi santralinin verimliliği açısından bölgesel ayrıma gidilerek verimliliği yüksek olan havzalardan verimliliği daha düşük olan havalara göre kamu teşvikleri artan oranlı desteklenebilir. Böylece rüzgar enerjisinin sadece belirli bir alanda kalmaktansa tüm ülkeye yaygınlaştırılması sağlanabilir.

$>$ Ülkemizde rüzgar türbinlerinin yerli imalatında mevcut desteklerin daha da artarak, dışa bağımlılığın azaltılması sağlanabilir. Böylece yüksek maliyetli bu tür türbinlerin daha düşük maliyetlerle ve ülkemiz koşullarına uygun şekilde hazırlanması sağlanabilir.

Enerji konusunda dışa bağımlılı̆̆ı çok yüksek olan bir ülke olan Türkiye'nin elindeki statik enerjiyi mutlaka kinetik enerjiye dönüştürmesi gereklidir. Sahip olduğu statik enerjiler arasında özellikle güneş ve rüzgar enerjisi yeşil ekonomi açısından ön plana çıkmaktadır. Bu kaynakların sürekliliği ve düşük maliyetli olmaları yatırım yapılması açısından bunları cazip kılmaktadır. Ülkemiz açısından da bu kaynaklar bakımından oldukça yüksek potansiyelin varlığı bilimsel olarak kabul edilmektedir. Güneş ve dünya var oldukça bitmeyecek ender kaynaklardan biri olan rüzgar enerjisi; doğru politikalarla ülkemizin enerji konusunda dışa bağımlılığını önemli ölçüde azaltabilecek ve dövizin yurtiçinde kalmasını sağlayabilecek düzeyde önem arz etmektedir.

\section{Kaynaklar}

Acar, E. ve Doğan A. (2008). Türkiye'nin Rüzgar ve Hidroelektrik Potansiyeli ve Çevresel Etkilerinin Değerlendirilmesi. VII. Ulusal Temiz Enerji Sempozyumu (UTES' 2008).

Altuntaşoğlu, Z.T. (2011), “Türkiye'de Rüzgar Enerjisi, Mevcut Durum, Sorunlar", Mühendis ve Makine Dergisi, 52(617), Ankara.

Ata R. (2010), "Yenilenebilir Enerji Kaynaklarından Jeotermal ve Rüzgar Enerjisinin Gelişimi ve Çevresel Değerlendirilmesi”, CBÜ Soma Meslek Yüksek Okulu Teknik Bilimler Dergisi, 2(13).

Aydın İ. (2013), "Balıkesir'de Rüzgar Enerjisi” Doğu Cografya Dergisi, 18(29). http://edergi.atauni.edu.tr/ataunidcd/article/view/1021009946/10210 07930, (erişim tarihi:29.10.2014)

Bayraç H. N. (2011), "Küresel Rüzgar Enerjisi Politikaları ve Uygulamaları", Uludağ Üniversitesi, İ̈BF Dergisi, XXX (1):37-57

Bozkurt, Y. (2010), Avrupa Birliği’ne Uyum Sürecinde Türkiye'de Çevre Politikalarının Dönüşümü, Birinci Baskı, Ekin Yayınevi, Bursa. 
A. Özen, M. Ü. Şaşmaz, E. Bahtiyar / KMÜ Sosyal ve Ekonomik Araştırmalar Dergisi 17 (28): 85-93, 2015

Carley S, S. Lawrence vd. (2011). "EnergyBasedEconomic Development" Renewable and Sustainable Energy Reviews, 15(1), ss.282-295.

Demirtaş I. (2012). Büyük Durgunluk ve Yeşil Ekonominin Yükselişi: Yeşil Ekonomi, Durgunluktan Çıkış İçin Alternatif Olabilir mi?, Üçüncü Uluslararası Ekonomi Konferans1, Türkiye Ekonomi Kurumu 1-3 Kasım 2012, İzmir. http://teacongress.org/papers2012/DEMIRTAS.pdf (erişim tarihi: 20.10.2014)

DPT. (1963). Birinci Beş Yıllık Kalkınma Planı, 19631967, Ankara.

DPT. (1967). İkinci Beş Yıllık Kalkınma Planı, 19681972, Ankara.

DPT. (1972). Üçüncü Beş Yıllık Kalkınma Planı, 19731977, Ankara.

DPT. (1978). Dördüncü Beş Yıllık Kalkınma Planı, 19791983, Ankara.

DPT. (1984). Beşinci Beş Yıllık Kalkınma Planı, 19851989, Ankara.

DPT. (1990). Altıncı Beş Yıllık Kalkınma Planı, 19901994, Ankara.

DPT. (1995). Yedinci Beş Yıllık Kalkınma Planı, 19962000, Ankara.

DPT. (2000). Sekizinci Beş Yıllık Kalkınma Planı, 20012005, Ankara.

DPT. (2006). Dokuzuncu Kalkınma Planı, 2007-2013, Ankara.

Global Wind Energy Council (2013), Global Wind Statistics,www.gwec.net,(E.T:30.10.2014).www.gwec.net/wp -content/uploads/2014/04/GWEC-Global-Wind-Report_9April-2014.pdf

Ha,H.(2011). “The Political Economy of EnergyBasedGreenEconomic Development: Policy Tools and Their Use for Local Energy Based Green Economic Development", The Florida StateUniversity.

http://unep.org/publications/ (erişim tarihi: 28.10.2014).

http://www.tureb.com.tr/tr/bilgi-bankasi/turkiye-resdurumu, (erişim tarihi:30.10.2014)

Kalkınma Bakanlığı. (2013). Onuncu Kalkınma Planı, 2014-2018, Ankara.

Karacan, A. R. (2012), Çevre Ekonomisi ve Politikası, Genişletilmiş İkinci Baskı, Ege Üniversitesi Basımevi, İzmir.

Karataş, S. (2009). Türkiye'de Yenilenebilir Enerji Kaynakları İçerisinde Rüzgar ve Güneş Enerjilerinin Yeri, İstanbul Üniversitesi Sosyal Bilimler Enstitüsü.

Koçaslan G. (2010), "Sürdürülebilir Kalkınma Hedefi Çerçevesinde Türkiye'nin Rüzgar Enerjisi Potansiyelinin Yeri ve Önemi”, Sosyal Bilimler Dergisi, (4)

Kuşat N. (2013). "Yeşil Sürdürülebilirlik İçin Yeşil Ekonomi: Avantaj ve Dezavantajlar1-Türkiye İncelemesi", Journal of Yasar University 2013 29(8) 4896-4916.

Okumuş, İ. (2013). Yeşil Ekonomi Göstergeleri Açısından Türkiye'nin Sürdürülebilir Kalkınma Performansı,
Yayınlanmamış Yüksek Lisans Tezi, Gaziantep Üniversitesi SBE.

Oskay C. (2014). "Sürdürülebilir Kalkınma Çerçevesinde Rüzgar Enerjisinin Önemi ve Türkiye'de Rüzgar Enerjisi Yatırımlarına Yönelik Teşvikler”, Niğde Üniversitesi IİBF Dergisi, 7(1)

T.C. Anayasası Kanun No: 2709 Kabul Tarihi: 7.11.1982.

T.C. Güney Ege Kalkınma Ajansı (2012), Enerji Sektörü Raporu, $\quad$ http://geka.org.tr/yukleme/planlama/Sektörel Araștırmalar/ Enerji Sektörü Raporu.pdf (erişim tarihi: 29.10.2014)

Türkiye Rüzgar Enerjisi Birliği, (2014), Türkiye Rüzgar Enerjisi Kongresi, 5-6 Kasim 2014, İstanbul, www.tureb.com.tr (erişim tarihi: 22.12.2014)

Uluatam Ela, (2010), "Yenilenebilir Enerji Teşvikleri", Ekonomik Forum Dergisi, TOBB, Ankara, (ss.34-41).

UNEP (2010). Green Economy Developing Countries Success Stories,

Genevawww.unep.org/pdf/greeneconomy_successstories. pdf (erişim tarihi:20.10.2014)

UNWCED (1987). Our Common Future, http://www.undocuments.net/wced-ocf.htm (erişim tarihi:02.12.2014)

http://www.alternaturk.org/ruzgar.php.(erişim tarihi:29.10.2014)

http://www.emo.org.tr/ekler/f03c8237bf6d4ab_ek.pdf. (erişim tarihi:01.04.2015)

http://www.eie.gov.tr/eieweb/turkce/YEK/ruzgar/ruzgar_ en_hak.html. (erişim:01.04.2015)

www.yildiz.edu.tr/ zyumur/duyurular.../ ekoteknolojiler \%20sunumu.ppt. (erişim:01.04.2015)

6094 Sayılı Yenilenebilir Enerji Kaynaklarının Elektrik Enerjisi Üretimi Amaçlı Kullanımına İlişkin Kanun 